\title{
Review of Current Dengue Treatment and Therapeutics in Development
}

\section{Fusco $\mathrm{DN}^{1 *}$ and Chung $\mathrm{RT}^{2}$}

${ }^{1}$ Department of Medicine, Massachusetts General Hospital, Boston, MA 02114

${ }^{2}$ Director of Hepatology, Gastrointestinal Unit-GI Associates, USA

\begin{abstract}
Dengue is an arthropod-borne flavivirus associated with hemorrhagic fever and hemorrhagic shock. Roughly one third of the world population lives at risk of dengue infection, and it is not possible to accurately predict which patients are at risk for severe or fatal infection. Currently, there is no treatment for dengue infection. However, several classes of agents are in under investigation as potential anti-dengue drugs, including direct antivirals, host modulators, and RNAi therapeutics. These anti-dengue drugs in development will be reviewed here.
\end{abstract}

\section{Introduction}

Dengue has been named one of the most important emerging infections in 2014 [1,2]. The geographic region at risk for dengue has increased fourfold over the past three decades, unprecedented for a vector-borne disease [2,3]. DENV is an arthropod-borne flavivirus associated with both hemorrhagic fever and hemorrhagic shock [4]. The classical clinical presentation of DENV is characterized by abrupt onset of headache, myalgia and high fever, in addition to arthralgia, retroorbital pain and hemorrhagic manifestations. The DENV hemorrhagic fever is characterized by fluid leakage into the intersistium. These symptoms are commonly seen in many other infectious diseases, which complicates diagnosis. DENV has also been implicated as a possible cause of multiple findings of end organ failure, including but not limited to: myocardial impairment (with arrhythmias and potential myocarditis), hepatitis with hepatic necrosis, maculopathy, rhabdomyolysis, multiple neurological manifestations, and fatal hemophagocytic lymphohistiocytosis [2,5-14]. 2.5 billion people live in DENV-endemic regions [4], and roughly 400 million infections occur per year with a case fatality rate exceeding $5-20 \%$ in some areas $[15,16]$. Over 100 countries are affected, including Europe and the United States [17]. As effective point of care (POC) diagnostics for malaria reach widespread utilization, the prevalence of non-malarial fevers, caused by dengue (DENV) and other infections, is increasingly noted in low and/or middle income countries (LMICs) $[18,19]$. DENV is endemic in many parts of Asia, and the DENV case frequency and fatalities in the Americas are increasing, where the total number of DENV cases reported quadrupled between the 1980s and 2000-2007 $[7,17,20]$. Furthermore, in recent years, infections in many LMICs are increasingly noted in adults, leading to significant number of work days lost and increasing costs to society [21].

Currently there is no specific treatment for DENV, recent hopeful vaccine candidates have just been deemed ineffective [22], and there is no prediction of complete vector control. However, rapid diagnosis followed by targeted vector control efforts decrease DENV transmission, and early detection followed by supportive care is reported to potentially decrease mortality rates from $5-20 \%$ to less than $1 \%[15,16,23]$. In many endemic regions, when a surge of dengue infections is suspected, public health authorities will circulate notices in local newspapers, transmits announcements via radio, and even close schools and other public facilities during peaks of transmission in attempts to decrease likely exposure. Other preventive measures include use of insecticide sprays and elimination of all mosquito breeding grounds (areas of standing water are cleared, particularly in schools). While attempts at early diagnosis paired with prevention are helpful, the combined lack of effective treatment for dengue and increasing dengue transmission are worrisome.

This review will focus on treatments in various stages of development for dengue, organized based on treatment strategy, including direct acting antiviral approaches, RNAi approaches, and host-modulators, and will attempt to complement other recent helpful reviews [5,24]. This review will not cover progress being made toward the challenging fields of DENV vaccine design, vector-targeted interventions, of which there are many, anti-dengue therapeutic antibodies [25], or studies related to precise selection of supportive care measures including choice of rescuscitation fluid, corticosteroid administration [26] or platelet transfusion decisions $[27,28]$. An excellent updated review of DENV vaccine work has recently been published [29]. Additional helpful recent reviews describing DENV treatment strategies under development are cited [5,24,30-32].

Information included in this review was supported by a search of the PubMed database for articles published in the English language using the search term "dengue treatment". In addition, bibliographies of the selected articles were reviewed for further relevant studies.

\section{Methods of Bioanalysis for Anti-dengue Activity}

\section{Pre-clinical}

Dengue is a positive stranded RNA virus with an $11 \mathrm{~kb}$ genome, encoding a polyprotein precursor cleaved to generate at least 10 proteins, including three structural proteins (core, membrane associated protein, and envelope protein), and seven nonstructural proteins (NS1, NS2a, NS2b, NS3, NS4b, NS5) (Figure 1) [33] . DENV is transmitted by silent, urban mosquito vectors, including Aedes aegypti and A. albopictus, A. polynesiensis and A. scutellaris, to man [3]. Other modes of transmission include via blood products, organ transplant, and vertical transmission [34-37]. There are four serotypes (1-4) of

*Corresponding author: Dahlene Fusco, MD, PhD, Department of Medicine Massachusetts General Hospital, Boston, MA 02114; E-mail: dnfusco@mgh. harvard.edu.

\section{Received May 02, 2014; Accepted May 29, 2014; Published May 31, 2014}

Citation: Fusco DN, Chung RT (2014) Review of Current Dengue Treatment and Therapeutics in Development. J Bioanal Biomed S8: 002. doi:10.4172/1948-593X S8-002

Copyright: ( 2014 Fusco DN, et al. This is an open-access article distributed under the terms of the Creative Commons Attribution License, which permits unrestricted use, distribution, and reproduction in any medium, provided the original author and source are credited. 


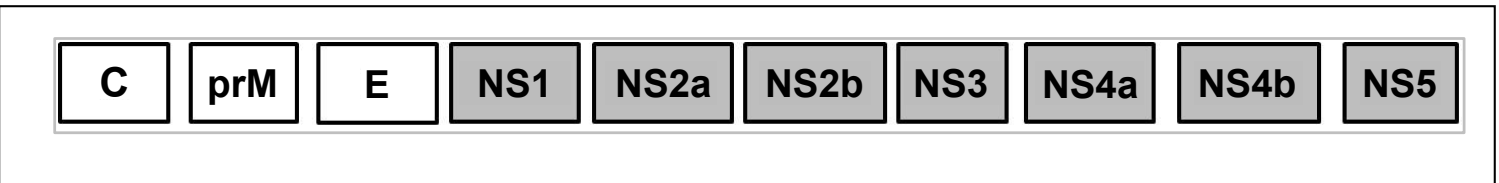

Figure 1: Schematic of the dengue virus polyprotein. The core (c), precursor membrane (prM), and envelope (E) proteins are structural proteins, whereas the remaining 7 proteins are non structural DENV proteins. NS1 is involved in RNA replication, NS2A participates in replication and assembly, NS2B serves as a cofactor for NS3, which is a serine protease, RNA helicase, 5'-RNA triphosphatase, and nucleoside triphosphatase. NS4A and 4B participate in replication, and NS5 serves as a methyl transferase and RNA-dependent RNA polymerase [1,5].

dengue, and multiple genotypes. All four serotypes infect man, and infection with one serotype does not confer protection against another serotype. In contrast, infection with a second dengue serotype appears to be, in some cases, enhanced by pre-existing antibodies generated from primary infection. This phenomenon is referred to as antibody dependent enhancement, or ADE $[5,38]$. In man, the initial cellular target of dengue is thought to be dendritic cells, followed by lymphatic spread and then distribution to monocytes and macrophages $[39,40]$. The full host of cells infected in vivo remain a subject of investigation, but may also include hepatocytes, myocytes, and other cell types [6,41]. In the laboratory, dengue can be cultivated in C6/36 mosquito cells or Vero African green monkey kidney cells, though intracellular modifications of the virus are thought to differ in these two systems, and are also affected by passage number, and therefore must be monitored $[42,43]$. Laboratory isolates of dengue can be used to infect several human cell lines, including but not limited to HepaRG human hepatoma cells, Huh7 human hepatoma cells, human foreskin fibrosblasts, U937 and THP-1 myeloid cells, HeLa human cervical carcinoma cells $[43,44]$. In order to infect monocyte cell lines, pre-incubation of virus with antidengue antibody can be used to take advantage of antibody dependent enhancement (ADE), which increases the amount of dengue infecting each individual cell $[5,38,43]$.

The level of dengue infectivity can then be monitored in vitro by multiple methods, including but not limited to plaque assay, qRT PCR, immunofluorescence, to identify compounds with antiviral activity. In addition to fully infectious dengue systems, in vitro reporter systems for dengue have been developed, and are also employed in assays seeking to identify dengue anti-virals [45-49]. The development of animal models of dengue virus (DENV) infection and disease has been challenging, since epidemic DENV does not naturally infect non-human species, but several models now exist, including the AG129 mouse (IFN alpha, beta, gamma knockout mouse), IFNAR1 knockout mouse, STAT2 knockout mouse, and, more recently, humanized BLT mouse [50-52].

\section{Clinical}

Clinical methods for evaluation of anti-dengue effects are in development. A major hurdle facing DENV clinical trials is the need for establishment of accurate diagnostic testing for case identification. However, current diagnostics for DENV available in the US and other high resource countries (PCR, IgM and IgG ELISA) are limited by a requirement for skilled workers, refrigeration, and specialized equipment $[3,53]$. Current point-of-care (POC) diagnostic tests for DENV are based on lateral flow detection of secreted DENV NS1 protein and IgM in blood/plasma/serum or saliva IgA [53,54]. NS1 assays are easy to use but limited in sensitivity, especially in secondary infections (common in endemic regions) [23,54], storage temperature, and cost $[3,53]$. IgG assays are limited in their inability to discriminate between recent and remote infection, and cannot detect early infection. Saliva IgA assays, alone, lack sensitivity during early primary DENV infection [23]. Because of these limitations, many LMIC sites with known endemic DENV are using clinical features, such as bleeding, leukopenia, or thrombocytopenia, and contextual epidemiological information to diagnose DENV at this time. Lack of precise diagnostic testing for DENV can lead to confusion in areas where malaria and yellow fever, which can include a similar presentation, are endemic, and can also serve as a barrier to regional participation in clinical trials, which currently represent the only potential mechanism of direct antiviral therapy, and further development and distribution of rapid diagnostic tests, coupled with test standardization, is in progress [53]. Recent clinical trials have included virologic (RT-PCR for DENV viral load and tests for secreted DENV NS-1 antigen) and immunologic measurements (multiple cytokine measurements). Because RT-PCR and cytokine assay technology may not be readily available at many dengue endemic sites, distribution of clinical trial efforts may be skewed. However, there is the possibility that increased DENV-drug design efforts will bring with them the benefit of technology transfer providing additional LMIC sites with these helpful resources.

\section{Treatment}

While current treatment for DENV is supportive care, there are multiple anti-DENV agents in various stages of development.

\section{Agents in Development for Anti-Dengue Activity}

\section{Direct acting antivirals}

RNA dependent RNA polymerase (NS5) inhibitors: $\mathrm{N}$-sulfonylanthranilic acid derivatives were identified as DENV RdRp inhibitors through screening of one million compounds using a primer extension RdRp assay [1]. The identified hit was found to bind DENV NS5 at the site of entrance to the RNA tunnel. While this specific compound is not under further development, the concept of inhibiting polymerase through the tunnel as well as other allosteric pockets is being pursued.

Nucleoside Analogues: Balapiravir (RG1626) is a prodrug of a nucleoside (cytidine) analog, R1479, which itself must be triphosphorylated for conversion into active form. Balapiravir was initially developed for the treatment of $\mathrm{HCV}$, but clinical trials were stopped due to toxicity during extended treatment courses (2-3 months) in combination with pegylated interferon and ribavirin [5557]. Because R1479 displayed in vitro anti dengue activity, and because of the shorter projected treatment duration for acute dengue infection (limiting toxicity), anti-dengue effects of balapiravir were explored in a phase II clinical trial [58]. An exploratory, dose-escalating, randomized placebo-controlled trial was conducted in adult male patients in Vietnam with dengue and $<48$ hours of fever. 32 subjects received five days of oral balapirivir ( 1500 or $3000 \mathrm{mg}$ ) for five days, and the medication was well tolerated. However, DENV viral loads, NS1 antigenemia, and fever clearance time were unaffected by treatment 
[58]. The authors accurately state that "although this trial, the first of its kind in dengue, does not support balapiravir as a candidate drug, it does establish a framework for antiviral treatment trials in dengue and provides the field with a clinically evaluated benchmark molecule" Subsequent analyses determined that when human PBMCs were preinfected with dengue (prior to balapiravir treatment), their ability to convert the prodrug balapiravir to the active, tri-phosphorylated nucleoside analog, R1479, form, was significantly impaired, resulting in decreased potency [59]. These in vitro studies also found that activation of NITD008, an adenosine based nucleoside analog [60], was less affected by dengue pre-infection, opening the possibility that further exploration of NITD008 may be warranted. A related compound, NITD203, was found to exhibit potent in vitro and in vivo anti-DENV efficacy, but satisfactory no-observable-adverse-effect levels could not be reached in 2 week in vivo toxicity studies [61].

Protease (NS2b-NS3) inhibitors: Recombinant retrocyclin 1. Rothan et al produced recombinant NS2B-NS3 protease in E. coli and identified recombinant retrocyclin 1, a cationic cyclic peptide theta defensing analogue with anti-HIV activity [62], as a potent DENV protease inhibitor [48].

BP13944: A screen of 60,000 chemical compounds in a DENV serotype 2 luciferase harboring replicon (BHK-21 cells) have recently identified BP13944, a quaternary ammonium salt, as an NS3 protease inhibitor [63].

a-ketoamides: Steuer et al designed an electrophilic trap for the serine component of the DENV NS2b-NS3 serine protease, and have identified $\alpha$-ketoamides as DENV protease inhibitors [64].

Quinoline containing compounds: Using virtual screening for DENV protease inhibitors followed by scaffold hopping, to expand chemical diversity, then a DENV luciferase reporter replicon assay, Deng et al have described 17 new compounds with NS2b-NS3 protease inhibitor activity, which can now serve as potential lead structures for further discovery efforts [65].

NS4b inhibitor. Van Cleef et al recently screened the NIH Clinical Collection of drug-like small molecules for anti-DENV activity in HeLa cells harboring a subgenomic DENV2-replicon reporter and identified the $\delta$ opioid receptor antagonist SDM25N as potent DENV inhibitor [66].

Methyltransferase (NS5) inhibitors: Using a fragment-based drug discovery approach, Coutard et al recently screened 500 drug-like fragments by thermal-sift assay for binding to the DENV NS3 helicase or NS5 methyltransferase, and identified 7 validated MTase binders, each containing 5-6 membered aromatic rings [67].

Translation inhibitors. Wang et al performed a high throughput screen for reduction or elimination of DENV CPE and identified benzomorphan compounds that inhibit DENV through suppression of RNA translation and also inhibit DENV viremia in mice, though higher doses were limited by toxicity [68].

Capsid inhibitor: A high throughput small molecule screen with readout of DENV induced CPE was performed on over 200,000 compounds and identified ST-148 as a unique inhibitor of the DENV capsid protein with both in vitro and in vivo effects (AG129 mice) [69].

Peptide Inhibitors of Various DENV proteins: Several groups have recently proposed the use of peptide inhibitors to block DENV infection [70-76]. For example, Lok et al have identified the mimetic peptide DN59, which corresponds to a region of the dengue virus envelope protein, as an inhibitor of all four serotypes of dengue virus [70]. They have found that DN59 incubation with DENV virus particles leads to viral membrane disruption and release of DENV RNA from the viral particles, but was non-toxic to mammalian cells [70]. In another study, 2 synthetic antiviral peptides were designed against target domain III of DENV2 envelope protein, and were found to exhibit significant DENV inhibition in vitro [73]. Prusis et al designed 45 peptide inhibitors against the DENV NS2b-NS3 protease and identified the tetrapeptide WCW-NH2 as an inhibitor of DENV 1-4 proteases [74].

\section{Host Modulators}

The compact $11 \mathrm{~kb}$ genome of DENV forces DENV to rely on multiple host factors for replication. This property can be exploited in attempts to inhibit viral replication through deprivation of these required host factors, or dependency factors. This strategy, targeting host factors to impede dengue viral infection, has recently been reviewed [30].

\section{Ribavirin}

Ribavirin is a broad acting inhibitor of RNA and DNA viruses. It is a synthetic guanosine analog which inhibits inosine monophosphate dehydrogenase with resulting GTP pool depletion [77], but has multiple additional proposed mechanisms of action, including up regulation of antiviral genes [78,79]. Ribavirin use has been limited by toxicity of both aerosolized and oral formulations, decreasing its clinical efficacy [80]. The complete compendium of downstream effectors of ribavirin antiviral effects is unknown. Ribavirin has been shown to have anti-DENV properties in several cell lines and primary cells $[81,82]$, and is often used as a positive control in cell culture assays for anti-DENV compounds. However, ribavirin was not demonstrated to have anti-DENV activity in either a mouse (AG129) or a primate model of DENV viremia $[83,84]$. However, more recent studies have described potentiation of sub-effective dose alpha glucosidase inhibitor CM-10-18 by ribavirin in AG129 mice, underscoring a possible role for ribavirin as a treatment enhancer, similar to its role in peg-IFN treatment of HCV [85].

\section{Mycophenolic Acid}

The immunosuppressive agent mycophenolic acid (MPA), a nonnucleoside inhibitor of IMP dehydrogenase, has also been shown to inhibit dengue in cell culture, reproduced in four hepatoma cell lines, by preventing synthesis and accumulation of viral RNA [86].

\section{Agents that Target Host Mediated Post Translational Modifications}

\section{a Glucosidase inhibitors}

Flavivirus assembly occurs at the host endoplasmic reticulum where DENV structural proteins prM and E colocalize to form an immature particle in the ER lumen, where a high mannose carbohydrate, (Glc)3(Man)9(GlcNAc)2, is added in the ER to specific asparagine residues on the prM and $\mathrm{E}$ proteins $[87,88]$. This carbohydrate is then modified by host $\alpha$-glucosidases to generate $\mathrm{N}$-linked glycans that lack the terminal $\alpha(1,2)$ and $\alpha(1,3)$ glucose residues [89]. It has been found that trimming these $\mathrm{N}$-linked carbohydrates in the ER may be required for DENV assembly or secretion of DEN [88,90,91]. a glucosidase inhibitors include the naturally occurring iminosugar castanospermine and also deoxynojirimycin, isolated from Bacillus. Castanospermine was found to inhibit infection with all four DENV serotypes in vitro, 
and also to prevent dengue mortality in an A/J DENV mouse model [88]. More recently, a pro-drug of castanospermine, 6-O-butanoyl castanospermine, or celgosivir, has found to fully protect AG129 mice from lethal infection with mouse adapted DENV when given up to $48 \mathrm{~h}$ following infection, and pharmacokinetic studies showed that celgosir is rapidly metabolized to castanospermine in mice [92,93]. A randomized, double-blind, placebo-controlled, phase $1 \mathrm{~b}$ clinical study to evaluate the activity, pharmacokinetics, safety and tolerability of celgosivir was conducted in adults with confirmed dengue fever in Singapore between 2012 and 2013 (ClinicalTrials.gov identifier NCT01619969). Results of that trial are anxiously awaited.

In parallel, another group examined the anti-DENV effects of the iminosugar drug UV-4, derived from deoxynojirimycin, in vivo in the AG129 mouse model, and found that UV-4 reduced mortality, DENV viremia, tissue levels of viral RNA, and virus induced cytokines, and that UV-4 also decreased mortality in an ADE model of secondary DENV infection [94]. Importantly, UV-4 treatment could be delayed up to 48 $\mathrm{h}$ in this mouse model, indicating its potential role as a therapeutic, though the therapeutic window is narrow because if administered at $72 \mathrm{~h}$ post infection, antiviral effects were no longer present [94]. In an outbreak setting, such early or possibly pre-emptive treatment could still be both feasible and useful. A phase I study of UV-4 opened in February 2014 (NCT02061358).

Other alpha glucosidase inhibitors, including $\mathrm{N}$-alkyldeoxynojirmcin derivatives [95] and a glucosidase substrate mimics, such as CM 978 and CM 10 18, are in development [85,96]. Perhaps one of the most exciting recent developments in the field, a recent study of co administration of the a glucosidase inhibitor CM1018 with ribavirin led to significant reduction of viremia in mice [85], for the first time providing data that the in vitro anti-DENV effects of ribavirin can be unlocked in vivo in the appropriate setting.

Cyclosporine blocks DENV NS5 interaction with the host dependency factor, cyclophilin, leading to DENV inhibition [97].

\section{Lovastatin}

Statins are inhibitors of 3-hydroxy-3-methylglutaryl coenzyme A (HMG-CoA) reductase, used for lipid lowering and mortality reduction in cardiovascular disease, and have an excellent safety profile $[98,99]$. Statins have been found to exhibit anti-DENV properties in both cell culture and mouse models [100-102]. A clinical trial examining the safety and antiviral properties of lovastatin in adult patients is now ongoing in Vietnam [103].

\section{Heparin and Heparan Sulfate}

It is interesting to note that highly sulfated heparan sulfate is involved in initial interactions between the DENV E glycoprotein and the host cell, and heparin and heparan sulfate like molecules have been found to have anti-DENV properties [104-111]. The important complexities of DENV infection and host coagulation state will not be explored in this review.

\section{Vitamin D}

Treatment of both monocytic (U937) and hepatic (Huh 7) cells with 1a, 25-dihydroxy-vitamin D3 was associated with decreased levels of DENV infection [112]

\section{Host Kinase Inhibitors}

Using an immunofluorescence imagebased assay suitable for identification of small molecule inhibitors of dengue virus infection and replication, Chu et al identified AZD0530 and dasatinib, inhibitors of Src and Abl kinases, as potent DENV inhibitors. More recently, this group has determined that AZD0530 and dasatinib inhibit DENV viral RNA replication through inhibition of the host dependency factor, Fyn kinase [113]. Of note, AZD0530 (saracatinib) is in advanced clinical trials, pending FDA approval, while dasatinib is FDA approved.

\section{Viral sensor (RIG-I and TLR3) agonists}

The innate immune system includes detection of viral RNA by the helicase domain of RIG-I [114,115]. A synthetic 5' triphosphate (5'ppp) RNA was designed to stimulate this host innate immune response as an antiviral therapeutic, and was found to have anti DENV effects when transfected into A549 cells as well as primary human monocytes prior to DENV infection [116]. Along a similar vein, Diwaker et al have recently identified the RIG-I inducer Rhodiola as an inhibitor of DENV in human peripheral blood mononuclear cells and the human monocytic cell THP1 cell line, when administered 2 hours after DENV infection [117]. Et al showed that TLR3 activation through administration of the dsRNA compound PIKA prior to DENV infection decreased DENV infection of HepG2 cells [118].

\section{Interferon}

The type 1 IFNs, including IFNa, are among the broadest acting antiviral therapeutics known [119]. IFNa is a current component of anti-HCV therapy and has also been used with success for hepatitis $\mathrm{B}$, severe acute respiratory syndrome, and WNV ([120-122]). Severe viral infection is often the result of subversion of the host immune response, rendering that response ineffective. A major common pathway of viral immune escape is suppression of the IFNa pathway (Figure 2) [33,123-143]. While IFN escape mechanisms vary from virus to virus, activation of IFN effectors downstream of viral subversion may identify common drug targets for restoration of an effective host antiviral response [30,144,145] (Figure 2). Although it will likely soon be possible to reduce reliance on IFNa in HCV treatment regimens [146-149], understanding the mechanism of this broad-acting antiviral will inform design of agents active against many viruses, such as DENV, that antagonize IFNa and for which no current treatment is available [124,126,132,134-137,150]. Elucidating the antiviral mechanism(s) of IFNa will also improve understanding of host-virus interactions, including variable human susceptibility to viruses and response to IFN or potential IFN-related therapies.

\section{IEG Activation will Circumvent Viral Subversion of IFN Signaling}

Type IIFN ( $\alpha$ and/or $\beta$ ) binds to the type 1 IFN receptor (IFNAR1/2), which interacts with JAK1/TYK2, which can be followed by activation of STAT1 and 2 and subsequent formation of the heterotrimeric complex IFN-stimulated gene factor 3, or ISGF3 (consisting of STAT1, STAT2, IRF9) (Figure 2) $[123,144]$. ISGF3 then translocates to the nucleus, and directs transcription of hundreds of IFN stimulated genes (ISGs) through an IFN stimulated response element (ISRE) [123]. When intact, this system is highly effective in limiting viral infection. However, many pathogenic viruses have evolved mechanisms to escape the type I IFN response [33,132,134-136,150,151]. For example, HCV inactivates a host protein required for endogenous IFN production (mitochondrial antiviral signaling protein (MAVS), also known as IPS-1 and VISA) [152,153]. Downstream of IFN production, HCV also inhibits the activity of IFN (endogenous or exogenous) [154]

In general, IFNa can successfully inhibit DENV if given preinfection, but not post-infection, due to DENV mediated suppression 


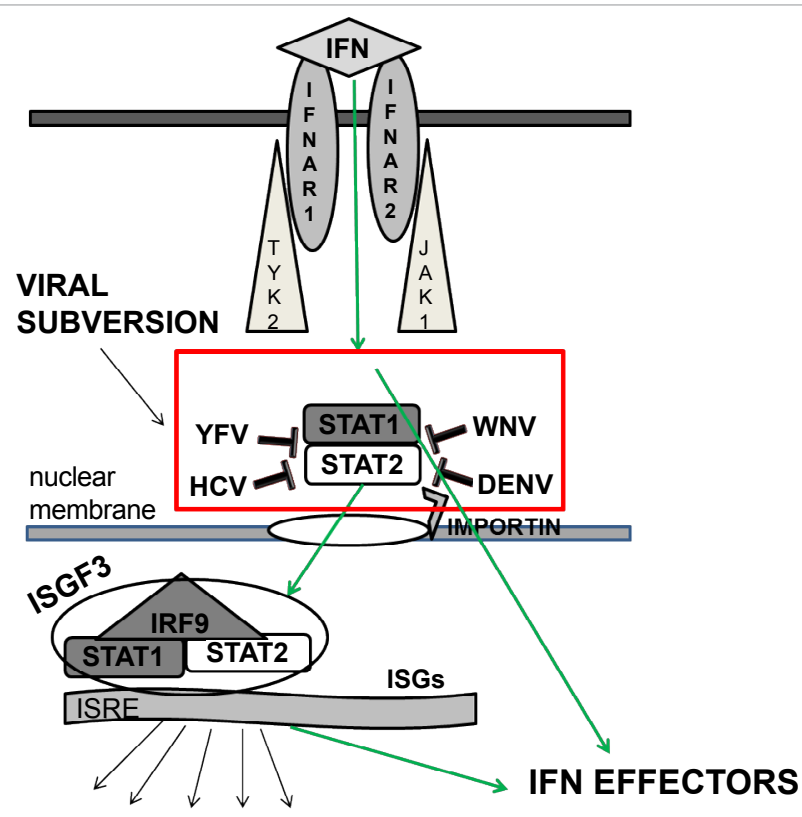

Figure 2: A subset of IEGs likely act downstream of viral subversion of IFN.IFN signaling events lead to upregulation of IFN stimulated genes (ISGs) via an IFN stimulated response element (ISRE). Viruses subvert early IFN signaling events through multiple mechanisms. For example, HCV core and NS5A proteins, and a conserved function of DENV, WNV, and YFV NS4B protein, all inhibit STAT1 activation by IFN (red box). We hypothesize that several IFN effectors activate downstream antiviral events that may circumvent this inhibition.

of early members of the IFN signaling pathway [140,155], though some antiviral effect was observed in post-infection administration of PEGrIFN-alpha-2a, which significantly lowered daily viremia levels and improved virus clearance, in rhesus monkeys [156]. Defining where viruses block, or subvert, the host IFN response can inform design of antivirals that act downstream of that block. In preliminary studies, we have identified 120 host antiviral candidates in a whole genome siRNA screen for HCV IEGs [44]. In addition, we have screened these 120 HCV IEG knockdowns for rescue of DENV from IFN in HeLa cells and have identified a subset of 45 HCV/DENV IEGs. Among our 45 HCV/DENV IEGs, we detected 6 known ISGs, including JAK1 and STAT2. While JAK1 and STAT2 lie proximal to likely subversion by Flaviridae (Figure 2), the remaining 4 DENV/HCV IEG/ISGs are likely downstream of this block, and may serve as candidates for IEG activation. Broad-acting IEG activation fits with criteria for identifying high-value targets for therapeutic intervention by (1) overcoming viral ability to inhibit IFN action or (2) acting downstream of the virusmediated IFN block. Because of their downstream location, such therapeutics could have fewer systemic effects than IFN itself, which would contribute to improved tolerability and therapeutic index. As host rather than virally targeted agents, these therapeutics are predicted to have a high barrier to viral resistance.

\section{D4 dopamine receptor antagonists}

Smith et al have identified a class of tricyclic small molecule compounds, the dihydrobenzothiepines (DHBTs), in a high throughput small molecule screen for DENV-2 inhibitors, using high content immunofluorescent assay readout in HEK293T cells $[157,158]$. They further determined that SKI-417616, a highly active DHBT, inhibited all 4 DENV serotypes in vitro at an early event in the DENV lifecycle, and identified the mechanism of activity as host $\mathrm{D} 4$ dopamine receptor inhibition. The authors suggest that, in vivo, macrophage-expressed dopamine receptors may be targettable DENV dependency factors.

\section{Ivermectin}

The anti-helminthic drug ivermectin has been identified as an inhibitor of the nuclear importer importin $\alpha / \beta$. Because DENV NS5 polymerase activity requires importin $\alpha / \beta$, anti-viral properties of ivermectin were explored, and revealed that pre-treatment with ivermectin inhibited DENV infection of Vero cells [159]. Supporting NS5 inhibitor effects of ivermectin, Tay et al. have found that ivermectin pretreatment strongly inhibits the nuclear localization of NS5 during DENV 1, 2 infection of BHK-21 or Huh-7 cells, along with inhibition of DENV infection levels [160]. At the same time, Mastrangelo et al identified ivermectin as a DENV NS3 helicase inhibitor using an in vitro modelled helicase inhibition assay, and further confirmed ivermectin anti-DENV activity, though only for virus yield reduction (qRT-PCR) and less so for CPE reduction [161].

\section{Pentoxifylline}

A small clinical trial of the TNFa inhibitor, pentoxifylline, showed a potential decrease in mean length of ICU stay and decreased TNFa levels, though viral parameters were not assessed [162].

\section{Chloroquine}

Chloroquine is an inexpensive, widely available, well-tolerated lysosomotropic 4-amino-quinoline derivative, which is well known as an anti-malarial drug but also possesses in vitro anti-viral activity, including anti-DENV activity, potentially related to its effect of increasing endosomal $\mathrm{pH}[163,164]$. In vitro, treatment with chloroquine caused a dose-dependent reduction of DV-1 infectivity in THP/DC-SIGN cells [165]. A clinical trial of anti-DENV efficacy of chloroquine was performed in Vietnam, where 154 adult patients with suspected dengue received $3 \mathrm{~d}$ chloroquine versus placebo. While a trend toward lower incidence of dengue hemorrhagic fever was detected, chloroquine did not reduce the duration of DENV viremia or NS1 antigenemia [166].

\section{Amodiaquine}

The quinoline derivative amodiaquine was recently identified in a replicon based screen for anti-DENV agents, and confirmed to have anti-DENV activity in DENV2 plaque assays and qRT PCR assaying for both intracellular and extracellular DENV levels [46].

\section{RNAi}

RNA interference, or RNAi, is a gene silencing process which degrades target RNA in a sequence specific fashion. RNAi has been proposed as a strategy to directly inhibit viral infections, including DENV [167-170]. One group showed that use of dendritic celltargeting peptide mediated delivery of siRNA against a conserved sequence in the DENV envelope effectively suppressed DENV replication in macrophages and monocytes [171]. In addition to RNAimediated suppression of DENV itself, RNAi-mediated suppression of viral dependency factors, or factor required by the virus for productive infection, has been shown to inhibit DENV [172,173]. There are currently no RNAi agents registered under clinicaltrials.gov when searched with dengue.

Interestingly, it has recently been found that the DENV NS4B protein of all four DENV serotypes acts as a suppressor of human intracellular RNAi machinery, including Dicer, Drosha, Ago1, and 
Citation: Fusco DN, Chung RT (2014) Review of Current Dengue Treatment and Therapeutics in Development. J Bioanal Biomed S8: 002. doi:10.4172/1948-593X.S8-002

Page 6 of 10

Ago2, as well as many human microRNAs [174]

\section{Morpholinos}

Taking advantage of the RNA-RNA or RNA-protein interactions required for DENV replication, antisense peptide-conjugated phosphorodiamidate morpholino oligomers (P-PMOs) have be designed to sterically interfere with these interactions [175-178]. Holden et al. evaluated the mechanism and effectiveness of DEN 5 ' stem loop, DEN 3' cyclization sequence, and one more novel morphilino complementary to the top of the DENV 3' stem loop. They found that the 5'SL P-PMO blocked DENV viral translation, the 3'CX P-PMO blocked viral RNA synthesis, and the novel 3' SLT P-PMO blocked both viral translation and RNA synthesis, and could potentially be useful as therapeutics in human infection.

\section{Other Compounds}

Other agents that have been suggested to display anti-dengue activity include geneticin, an aminoglycoside antibiotic, which has been found to have the unique property, among aminoglycosides, of inhibiting DENV [179] and FCI 106, a compound of unknown mechanism identified in a screen for anti-Ebola agents, which has also been found to have anti-DENV activity, in DC-SIGN cells [180].

\section{Medicinal plant derivatives}

There is a significant amount of research dedicated to hypothesisdriven and practice-based identification of naturally occurring compounds with anti-dengue properties. While this literature will not be reviewed extensively here, several recent references are indicated [181187]. It is important to note that many of the compounds examined in these studies are selected because they are already in use against dengue in traditional settings, underscoring the need to examine their effect on dengue-related outcomes, regardless of whether they will be assessed for drug development.

\section{Summary}

In summary, dengue virus has emerged as an increasingly worrisome arboviral disease, with 2.5 billion people currently living in regions at risk of disease, and innumerable others exposed through travel, with no realistic optimism of near-term vaccine or vector control, and incomplete understanding of factors predicting who will succumb to fatal infection. There are multiple leads for antiviral design advancing through the therapeutic development pipeline, and clinical trials are beginning. Major challenges ahead will include identification of compounds that validate in vivo [68], exhibit a highly favorable safety profile, are active beyond the earliest hours of infection, are inexpensive, and unlikely to be overcome by viral resistance. There is a significant amount of work to be done.

\section{References}

1. Niyomrattanakit $P$, Chen $Y L$, Dong H, Yin Z, Qing M, et al. (2010) Inhibition of dengue virus polymerase by blocking of the RNA tunnel. J Virol 84: 5678-5686.

2. Yacoub S, Wertheim H, Simmons CP, Screaton G, Wills B (2014) Cardiovascular manifestations of the emerging dengue pandemic. Nat Rev Cardiol 11: 335-345.

3. Mayxay M, Castonguay-Vanier J, Chansamouth V2, Dubot-Peres A, Paris DH4, et al. (2013) Causes of non-malarial fever in Laos: a prospective study. Lancet Glob Health 1: e46-46e54.

4. Guzman MG, Halstead SB, Artsob H, Buchy P, Farrar J, et al. (2010) Dengue: a continuing global threat. Nat Rev Microbiol 8: S7-16.

5. Julander JG, Perry ST, Shresta S (2011) Important advances in the field of anti- dengue virus research. Antivir Chem Chemother 21: 105-116

6. Kularatne SA, Imbulpitiya IV, Abeysekera RA, Waduge RN, Rajapakse RP, et al. (2014) Extensive haemorrhagic necrosis of liver is an unpredictable fatal complication in dengue infection: a postmortem study. BMC Infect Dis 14: 141

7. Sharp TM, Gaul L, Muehlenbachs A, Hunsperger E, Bhatnagar J, et al. (2014) Fatal hemophagocytic lymphohistiocytosis associated with locally acquired dengue virus infection - New Mexico and Texas, 2012. MMWR Morb Mortal Wkly Rep 63: 49-54.

8. Luk FO, Chan CK, Lai TY (2013) A case of dengue maculopathy with spontaneous recovery. Case Rep Ophthalmol 4: 28-33.

9. Sargeant T, Harris T, Wilks R, Barned S, Galloway-Blake K, et al. (2013) Rhabdomyolysis and dengue Fever: a case report and literature review. Case Rep Med 2013: 101058.

10. Joshi R, Phatarpekar A, Currimbhoy Z, Desai M (2011) Haemophagocytic lymphohistiocytosis: a case series from Mumbai. Ann Trop Paediatr 31: 135140.

11. Puccioni-Sohler M, Orsini M, Soares CN (2012) Dengue: a new challenge for neurology. Neurol Int 4: e15.

12. Ramachandran B, Balasubramanian S, Abhishek N, Ravikumar KG, Ramanan AV (2011) Profile of hemophagocytic lymphohistiocytosis in children in a tertiary care hospital in India. Indian Pediatr 48: 31-35.

13. Larik A, Chiong Y, Lee LC, Ng YS (2012) Longitudinally extensive transverse myelitis associated with dengue fever. BMJ Case Rep 2012.

14. Bowman S, Salgado C, DeWaay DJ (2012) Dengue fever presenting with hepatitis. Am J Med Sci 344: 335-336.

15. http://www.cdc.gov/dengue/

16. Linares EM, Pannuti CS, Kubota LT, Thalhammer S (2013) Immunospot assay based on fluorescent nanoparticles for Dengue fever detection. Biosens Bioelectron 41: 180-185

17. San Martín JL, Brathwaite O, Zambrano B, Solórzano JO, Bouckenooghe A et al. (2010) The epidemiology of dengue in the americas over the last three decades: a worrisome reality. Am J Trop Med Hyg 82: 128-135.

18. Chappuis F, Alirol E, d'Acremont V, Bottieau E, Yansouni CP (2013) Rapid diagnostic tests for non-malarial febrile illness in the tropics. Clin Microbio Infect 19: 422-431.

19. Stoler J, AI Dashti R2, Anto F3, Fobil JN4, Awandare GA5 (2014) Deconstructing "malaria": West Africa as the next front for dengue fever surveillance and control. Acta Trop 134C: 58-65

20. Añez G, Rios M (2013) Dengue in the United States of America: a worsening scenario? Biomed Res Int 2013: 678645.

21. Stahl HC, Butenschoen VM, Tran HT, Gozzer E, Skewes R, et al. (2013) Cost of dengue outbreaks: literature review and country case studies. BMC Public Health 13: 1048

22. Mahalingam S, Herring BL, Halstead SB (2013) Call to action for dengue vaccine failure. Emerg Infect Dis 19: 1335-1337.

23. Yap G, Sil BK, Ng LC (2011) Use of saliva for early dengue diagnosis. PLoS Negl Trop Dis 5: e1046.

24. De Clercq $E$ (2010) Strategies for the treatment of dengue virus infections: a narrative account. Future Med Chem 2: 601-608.

25. Poungpair O, Bangphoomi K2, Chaowalit $P$, Sawasdee N, Saokaew N3, et al. (2014) Generation of human single-chain variable fragment antibodies specific to dengue virus non-structural protein 1 that interfere with the virus infectious cycle. MAbs 6: 474-482.

26. Tam DT, Ngoc TV, Tien NT, Kieu NT, Thuy TT et al. Effects of short-course oral corticosteroid therapy in early dengue infection in Vietnamese patients: a randomized, placebo-controlled trial. Clin Infect Dis 2012. 55: 1216-1224.

27. Kurukularatne C, Dimatatac F, Teo DL, Lye DC, Leo YS (2011) When less is more: can we abandon prophylactic platelet transfusion in Dengue fever? Ann Acad Med Singapore 40: 539-545.

28. Khan Assir MZ, Kamran U, Ahmad HI, Bashir S, Mansoor H, et al. (2013) Effectiveness of platelet transfusion in dengue Fever: a randomized controlled trial. Transfus Med Hemother 40: 362-368. 
Citation: Fusco DN, Chung RT (2014) Review of Current Dengue Treatment and Therapeutics in Development. J Bioanal Biomed S8: 002. doi:10.4172/1948-593X.S8-002

29. Thomas SJ (2014) Developing a dengue vaccine: progress and future challenges. Ann N Y Acad Sci

30. Krishnan MN, Garcia-Blanco MA2 (2014) Targeting host factors to treat West Nile and dengue viral infections. Viruses 6: 683-708.

31. Pastorino B, Nougairède A, Wurtz N, Gould E, de Lamballerie X (2010) Role of host cell factors in flavivirus infection: Implications for pathogenesis and development of antiviral drugs. Antiviral Res 87: 281-294.

32. Sayce AC, Miller JL, Zitzmann N (2010) Targeting a host process as an antiviral approach against dengue virus. Trends Microbiol 18: 323-330.

33. Muñoz-Jordan JL, Sánchez-Burgos GG, Laurent-Rolle M, García-Sastre A (2003) Inhibition of interferon signaling by dengue virus. Proc Natl Acad Sci U S A 100: 14333-14338.

34. Wilder-Smith A, Chen LH, Massad E, Wilson ME (2009) Threat of dengue to blood safety in dengue-endemic countries. Emerg Infect Dis 15: 8-11.

35. Stramer SL, Hollinger FB, Katz LM, Kleinman S, Metzel PS, et al. (2009) Emerging infectious disease agents and their potential threat to transfusion safety. Transfusion 49 Suppl 2: 1S-29S.

36. Teo D, Ng LC, Lam S (2009) Is dengue a threat to the blood supply? Transfus Med 19: 66-77.

37. Wiwanitkit $\mathrm{V}$ (2009) Unusual mode of transmission of dengue. J Infect Dev Ctries 4: 51-54

38. Mathew A, Rothman AL (2008) Understanding the contribution of cellular immunity to dengue disease pathogenesis. Immunol Rev 225: 300-313.

39. Wong KL, Chen W, Balakrishnan T, Toh YX, Fink K, et al. (2012) Susceptibility and response of human blood monocyte subsets to primary dengue virus infection. PLoS One 7: e36435.

40. Anna PD, José MV, Wanionek K, Samantha NH, Gordon A et al. (2008) Phenotyping of peripheral blood mononuclear cells during acute dengue illness demonstrates infection and increased activation of monocytes in severe cases compared to classic dengue fever. Virology 376: 429-35.

41. Warke RV, Becerra A, Zawadzka A, Schmidt DJ, Martin KJ et al. (2008) Efficient dengue virus (DENV) infection of human muscle satellite cells upregulates type I interferon response genes and differentially modulates $\mathrm{MHC}$ I expression on bystander and DENV-infected cells. J Gen Virol 89: 1605-1615.

42. Lee E, Weir RC, Dalgarno L (1997) Changes in the dengue virus major envelope protein on passaging and their localization on the three-dimensional structure of the protein. Virology 232: 281-290.

43. Diamond MS, Edgil D, Roberts TG, Lu B, Harris E (2000) Infection of human cells by dengue virus is modulated by different cell types and viral strains. $J$ Virol 74: 7814-7823.

44. Fusco DN, Brisac C, John SP, Huang YW, Chin CR, et al. (2013) A genetic screen identifies interferon-Ît effector genes required to suppress hepatitis C virus replication. Gastroenterology 144: 1438-1449, 1449.

45. Massé N, Davidson A, Ferron F, Alvarez K, Jacobs M et al. (2010) Dengue virus replicons: production of an interserotypic chimera and cell lines from different species, and establishment of a cell-based fluorescent assay to screen inhibitors, validated by the evaluation of ribavirin's activity. Antiviral Res 86: 296-305.

46. Boonyasuppayakorn S, Reichert ED2, Manzano M3, Nagarajan K4 Padmanabhan R5 (2014) Amodiaquine, an antimalarial drug, inhibits dengue virus type 2 replication and infectivity. Antiviral Res 106: 125-134.

47. Rothan HA, Abdulrahman AY, Sasikumer PG, Othman S, Rahman NA, et al. (2012) Protegrin-1 inhibits dengue NS2B-NS3 serine protease and viral replication in MK2 cells. J Biomed Biotechnol 2012: 251482.

48. Rothan HA, Han HC, Ramasamy TS, Othman S, Rahman NA, et al. (2012) Inhibition of dengue NS2B-NS3 protease and viral replication in Vero cells by recombinant retrocyclin-1. BMC Infect Dis 12: 314

49. Bhattacharyya A, Trotta CR, Peltz SW (2007) Mining the GEMS--a nove platform technology targeting post-transcriptional control mechanisms. Drug Discov Today 12: 553-560.

50. Frias-Staheli N, Dorner M, Marukian S, Billerbeck E, Labitt RN, et al. (2014) Utility of humanized BLT mice for analysis of dengue virus infection and antiviral drug testing. J Virol 88: 2205-2218.
51. Watanabe S, Vasudevan SG (2014) Evaluation of dengue antiviral candidates in vivo in mouse model. Methods Mol Biol 1138: 391-400.

52. Zompi S, Harris E (2012) Animal models of dengue virus infection. Viruses 4 $62-82$

53. Blacksell SD (2012) Commercial dengue rapid diagnostic tests for point-of-care application: recent evaluations and future needs? J Biomed Biotechnol 2012 151967

54. Tan YY, Sekaran SD, Wang SM, Ahmed F, Hossain A, et al. (2011) Development of ASSURE Dengue IgA Rapid Test for the Detection of Anti-dengue IgA from Dengue Infected Patients. J Glob Infect Dis 3: 233-240.

55. Brandl M, Wu X, Holper M, Hong L, Jia Z, et al. (2008) Physicochemical properties of the nucleoside prodrug R1626 leading to high oral bioavailability. Drug Dev Ind Pharm 34: 683-691.

56. Klumpp K, Lévêque V, Le Pogam S, Ma H, Jiang WR, et al. (2006) The nove nucleoside analog R1479 (4'-azidocytidine) is a potent inhibitor of NS5Bdependent RNA synthesis and hepatitis $\mathrm{C}$ virus replication in cell culture. J Bio Chem 281: 3793-3799.

57. Roberts SK, Cooksley G, Dore GJ, Robson R, Shaw D, et al. (2008) Robust antiviral activity of R1626, a novel nucleoside analog: a randomized, placebocontrolled study in patients with chronic hepatitis C. Hepatology 48: 398-406.

58. Nguyen NM, Tran CN, Phung LK, Duong KT, Huynh Hle A, et al. (2013) A randomized, double-blind placebo controlled trial of balapiravir, a polymerase inhibitor, in adult dengue patients. J Infect Dis 207: 1442-1450.

59. Chen YL, Abdul Ghafar N, Karuna R, Fu Y, Lim SP, et al. (2014) Activation of peripheral blood mononuclear cells by dengue virus infection depotentiates balapiravir. J Virol 88: 1740-1747.

60. Yin Z, Chen YL, Schul W, Wang QY, Gu F, et al. (2009) An adenosine nucleoside inhibitor of dengue virus. Proc Natl Acad Sci U S A 106: 2043520439.

61. Chen YL, Yin Z, Lakshminarayana SB, Qing M, Schul W, et al. (2010) Inhibition of dengue virus by an ester prodrug of an adenosine analog. Antimicrob Agents Chemother 54: 3255-3261.

62. Daly NL, Chen YK, Rosengren KJ, Marx UC, Phillips ML, et al. (2007) Retrocyclin-2: structural analysis of a potent anti-HIV theta-defensin. Biochemistry 46: 9920-9928.

63. Yang CC, Hu HS, Wu RH, Wu SH, Lee SJ, et al. (2014) A novel dengue virus inhibitor, BP13944, discovered by high-throughput screening with dengue virus replicon cells selects for resistance in the viral NS2B/NS3 protease. Antimicrob Agents Chemother 58: 110-119.

64. Steuer C, Gege C, Fischl W, Heinonen KH, Bartenschlager R, et al. (2011) Synthesis and biological evaluation of alpha-ketoamides as inhibitors of the Dengue virus protease with antiviral activity in cell-culture. Bioorg Med Chem 19: $4067-4074$

65. Deng J, Li N, Liu H, Zuo Z, Liew OW, et al. (2012) Discovery of novel smal molecule inhibitors of dengue viral NS2B-NS3 protease using virtual screening and scaffold hopping. J Med Chem 55: 6278-6293.

66. van Cleef KW, Overheul GJ, Thomassen MC, Kaptein SJ, Davidson AD, et al (2013) Identification of a new dengue virus inhibitor that targets the viral NS4B protein and restricts genomic RNA replication. Antiviral Res 99: 165-171.

67. Coutard B, Decroly E, Li C, Sharff A, Lescar J, et al. (2014) Assessment of Dengue virus helicase and methyltransferase as targets for fragment-based drug discovery. Antiviral Res 106: 61-70.

68. Wang QY, Kondreddi RR, Xie X, Rao R, Nilar S, et al. (2011) A translation inhibitor that suppresses dengue virus in vitro and in vivo. Antimicrob Agents Chemother 55: 4072-4080.

69. Byrd CM, Dai D, Grosenbach DW, Berhanu A, Jones KF, et al. (2013) A nove inhibitor of dengue virus replication that targets the capsid protein. Antimicrob Agents Chemother 57: 15-25.

70. Lok SM, Costin JM, Hrobowski YM, Hoffmann AR, Rowe DK, et al. (2012) Release of dengue virus genome induced by a peptide inhibitor. PLoS One 7: e50995.

71. Hrobowski YM, Garry RF, Michael SF (2005) Peptide inhibitors of dengue virus and West Nile virus infectivity. Virol J 2: 49. 
Citation: Fusco DN, Chung RT (2014) Review of Current Dengue Treatment and Therapeutics in Development. J Bioanal Biomed S8: 002. doi:10.4172/1948-593X.S8-002

72. Schmidt AG, Yang PL, Harrison SC (2010) Peptide inhibitors of dengue-virus entry target a late-stage fusion intermediate. PLoS Pathog 6: e1000851.

73. Alhoot MA, Rathinam AK, Wang SM, Manikam R, Sekaran SD (2013) Inhibition of dengue virus entry into target cells using synthetic antiviral peptides. Int J Med Sci 10: 719-729.

74. Prusis P, Junaid M, Petrovska R, Yahorava S, Yahorau A, et al. (2013) Design and evaluation of substrate-based octapeptide and non substrate-based tetrapeptide inhibitors of dengue virus NS2B-NS3 proteases. Biochem Biophys Res Commun 434: 767-772.

75. Panya A, Bangphoomi K, Choowongkomon K, Yenchitsomanus PT (2014) Peptide Inhibitors Against Dengue Virus Infection. Chem Biol Drug Des

76. Parikesit AA, Kinanty, Tambunan US (2013) Screening of commercial cyclic peptides as inhibitor envelope protein dengue virus (DENV) through molecular docking and molecular dynamics. Pak J Biol Sci 16: 1836-1848.

77. Leyssen P, Balzarini J, De Clercq E, Neyts J (2005) The predominant mechanism by which ribavirin exerts its antiviral activity in vitro against flaviviruses and paramyxoviruses is mediated by inhibition of IMP dehydrogenase. J Virol 79 1943-1947.

78. Zhang Y, Jamaluddin M, Wang S, Tian B et al. (2003) Ribavirin treatment up-regulates antiviral gene expression via the interferon-stimulated response element in respiratory syncytial virus-infected epithelial cells. J Virol 77: 59335947.

79. Thomas E, Ghany MG, Liang TJ (2012) The application and mechanism of action of ribavirin in therapy of hepatitis $C$. Antivir Chem Chemother 23: 1-12.

80. Empey KM, Peebles RS Jr, Kolls JK (2010) Pharmacologic advances in the treatment and prevention of respiratory syncytial virus. Clin Infect Dis 50: 12581267.

81. Takhampunya R, Ubol S, Houng HS, Cameron CE, Padmanabhan R (2006) Inhibition of dengue virus replication by mycophenolic acid and ribavirin. J Gen Virol 87: 1947-1952.

82. Huang YH, Lei HY, Liu HS, Lin YS, Liu CC, et al. (2000) Dengue virus infects human endothelial cells and induces IL-6 and IL-8 production. Am J Trop Med Hyg 63: 71-75.

83. Malinoski FJ, Hasty SE, Ussery MA, Dalrymple JM (1990) Prophylactic ribavirin treatment of dengue type 1 infection in rhesus monkeys. Antiviral Res 13: 139149.

84. Schul W, Liu W, Xu HY, Flamand M, Vasudevan SG (2007) A dengue fever viremia model in mice shows reduction in viral replication and suppression of the inflammatory response after treatment with antiviral drugs. J Infect Dis 195 $665-674$

85. Chang J, Schul W, Butters TD, Yip A, Liu B, et al. (2011) Combination of $\hat{I} \pm$ glucosidase inhibitor and ribavirin for the treatment of dengue virus infection in vitro and in vivo. Antiviral Res 89: 26-34.

86. Diamond MS, Zachariah M, Harris E (2002) Mycophenolic acid inhibits dengue virus infection by preventing replication of viral RNA. Virology 304: 211-221.

87. Chambers TJ, Hahn CS, Galler R, Rice CM (1990) Flavivirus genome organization, expression, and replication. Annu Rev Microbiol 44: 649-688.

88. Whitby K, Pierson TC, Geiss B, Lane K, Engle M, et al. (2005) Castanospermine a potent inhibitor of dengue virus infection in vitro and in vivo. J Virol 79: 86988706.

89. Hebert DN, Foellmer B, Helenius A (1996) Calnexin and calreticulin promote folding, delay oligomerization and suppress degradation of influenza hemagglutinin in microsomes. EMBO J 15: 2961-2968.

90. Courageot MP, Frenkiel MP, Dos Santos CD, Deubel V, Desprès P (2000) Alpha-glucosidase inhibitors reduce dengue virus production by affecting the initial steps of virion morphogenesis in the endoplasmic reticulum. J Virol 74 564-572.

91. Wu SF, Lee CJ, Liao CL, Dwek RA, Zitzmann N, et al. (2002) Antiviral effects of an iminosugar derivative on flavivirus infections. J Virol 76: 3596-3604

92. Watanabe S, Rathore AP, Sung C, Lu F, Khoo YM et al. (2012) Dose- and schedule-dependent protective efficacy of celgosivir in a lethal mouse model for dengue virus infection informs dosing regimen for a proof of concept clinical trial. Antiviral Res 96: 32-35.

93. Rathore AP, Paradkar PN, Watanabe S, Tan KH, Sung C, et al. (2011)
Celgosivir treatment misfolds dengue virus NS protein, induces cellular prosurvival genes and protects against lethal challenge mouse model. Antiviral Res 92: 453-460.

94. Perry ST, Buck MD, Plummer EM, Penmasta RA, Batra H, et al. (2013) An iminosugar with potent inhibition of dengue virus infection in vivo. Antiviral Res 98: $35-43$

95. Du Y, Ye H, Gill T, Wang L, Guo F, et al. (2013) N-Alkyldeoxynojirimycin derivatives with novel terminal tertiary amide substitution for treatment of bovine viral diarrhea virus (BVDV), Dengue, and Tacaribe virus infections. Bioorg Med Chem Lett 23: 2172-2176.

96. Chang J, Schul W, Yip A, Xu X, Guo JT, et al. (2011) Competitive inhibitor of cellular Î士-glucosidases protects mice from lethal dengue virus infection. Antiviral Res 92: 369-371.

97. Qing M, Yang F, Zhang B, Zou G, Robida JM et al. (2009) Cyclosporine inhibits flavivirus replication through blocking the interaction between host cyclophilins and viral NS5 protein. Antimicrob Agents Chemother, 53: 3226-35.

98. Brookes ZL, McGown CC, Reilly CS (2009) Statins for all: the new premed? B J Anaesth 103: 99-107.

99. Pasternak RC, Smith SC Jr, Bairey-Merz CN, Grundy SM, Cleeman JI, et al. (2002) ACC/AHA/NHLBI Clinical Advisory on the Use and Safety of Statins. Stroke 33: 2337-2341.

100. Martínez-Gutierrez M, Castellanos JE, Gallego-Gómez JC (2011) Statins reduce dengue virus production via decreased virion assembly. Intervirology 54: 202-216.

101. Martinez-Gutierrez M, Correa-Londoño LA2, Castellanos JE3, GallegoGómez JC4, Osorio JE5 (2014) Lovastatin delays infection and increase survival rates in AG129 mice infected with dengue virus serotype 2. PLoS One 9: e87412.

102. Rothwell C, Lebreton A, Young Ng C, Lim JY, Liu W, et al. (2009) Cholesterol biosynthesis modulation regulates dengue viral replication. Virology 389: 8-19.

103. Whitehorn J, Van Vinh Chau N, Truong NT, Tai LT, Van Hao N, et al. (2012) Lovastatin for adult patients with dengue: protocol for a randomised controlled trial. Trials 13: 203

104. Chen Y, Maguire T, Hileman RE, Fromm JR, Esko JD, et al. (1997) Dengue virus infectivity depends on envelope protein binding to target cell heparan sulfate. Nat Med 3: 866-871.

105. Germi R, Crance JM, Garin D, Guimet J, Lortat-Jacob H, et al. (2002) Heparan sulfate-mediated binding of infectious dengue virus type 2 and yellow fever virus. Virology 292: 162-168.

106. Ono L, Wollinger W, Rocco IM, Coimbra TL, Gorin PA, et al. (2003) In vitro and in vivo antiviral properties of sulfated galactomannans against yellow fever virus (BeH11 strain) and dengue 1 virus (Hawaii strain). Antiviral Res 60: 201208.

107. Talarico LB, Damonte EB (2007) Interference in dengue virus adsorption and uncoating by carrageenans. Virology 363: 473-485.

108. Talarico LB, Pujol CA, Zibetti RG, Faría PC, Noseda MD, et al. (2005) The antiviral activity of sulfated polysaccharides against dengue virus is dependent on virus serotype and host cell. Antiviral Res 66: 103-110.

109. Talarico LB, Noseda MD, Ducatti DR, Duarte ME, Damonte EB (2011) Differential inhibition of dengue virus infection in mammalian and mosquito cells by iota-carrageenan. J Gen Virol 92: 1332-1342.

110. Chen J, Yamada S, Hama Y, Shetty AK, Kobayashi T, et al. (2011) Unique heparan sulfate from shrimp heads exhibits a strong inhibitory effect on infections by dengue virus and Japanese encephalitis virus. Biochem Biophys Res Commun 412: 136-142.

111. Lin YL, Lei HY, Lin YS, Yeh TM, Chen SH, et al. (2002) Heparin inhibits dengue-2 virus infection of five human liver cell lines. Antiviral Res 56: 93-96.

112. Puerta-Guardo $H$, Medina F, De la Cruz Hernández SI, Rosales VH, Ludert JE, et al. (2012) The 1 1 I,25-dihydroxy-vitamin D3 reduces dengue virus infection in human myelomonocyte (U937) and hepatic (Huh-7) cell lines and cytokine production in the infected monocytes. Antiviral Res 94: 57-61.

113. de Wispelaere M, LaCroix AJ, Yang PL (2013) The small molecules AZD0530 and dasatinib inhibit dengue virus RNA replication via Fyn kinase. J Virol 87 7367-7381. 
Citation: Fusco DN, Chung RT (2014) Review of Current Dengue Treatment and Therapeutics in Development. J Bioanal Biomed S8: 002. doi:10.4172/1948-593X.S8-002

114. Jiang F, Ramanathan A, Miller MT, Tang GQ, Gale M Jr, et al. (2011) Structural basis of RNA recognition and activation by innate immune receptor RIG-I. Nature 479: 423-427.

115. Yoneyama M, Fujita T (2007) Function of RIG-I-like receptors in antiviral innate immunity. J Biol Chem 282: 15315-15318.

116. Goulet ML, Olagnier D, Xu Z, Paz S, Belgnaoui SM, et al. (2013) Systems analysis of a RIG-I agonist inducing broad spectrum inhibition of virus infectivity. PLoS Pathog 9: e1003298.

117. Diwaker D, Mishra KP, Ganju L, Singh SB (2014) Rhodiola inhibits dengue virus multiplication by inducing innate immune response genes RIG-I, MDA5 and ISG in human monocytes. Arch Virol

118. Zhang P, Wu S, Li L, Liang Z, Li Y, et al. (2013) Adjuvant PIKA protects hepatoma cells from dengue virus infection by promoting a TBK-1-dependent innate immune response. Arch Virol 158: 829-838.

119. ISAACS A, LINDENMANN J (1957) Virus interference. I. The interferon. Proc R Soc Lond B Biol Sci 147: 258-267.

120. Dusheiko G (2013) Treatment of HBeAg positive chronic hepatitis B: interferon or nucleoside analogues. Liver Int 33 Suppl 1: 137-150.

121. Mazzulli T, Kain K, Butany J (2004) Severe acute respiratory syndrome: overview with an emphasis on the Toronto experience. Arch Pathol Lab Med 128: $1346-1350$.

122. Rahal JJ (2005) Methods of Treating West Nile Virus Infection, The New York Hospital Medical Center of Queens, Flushing, NY (US): US.

123. Wang BX, Fish EN (2012) The yin and yang of viruses and interferons. Trends Immunol 33: 190-197.

124.Dong C, Zafrullah M, Mixson-Hayden T, Dai X, Liang J, et al. (2012) Suppression of interferon-l̂̀ signaling by hepatitis $\mathrm{E}$ virus. Hepatology 55 : 1324-1332.

125. Bellecave P, Sarasin-Filipowicz M, Donzé O, Kennel A, Gouttenoire J, et al. (2010) Cleavage of mitochondrial antiviral signaling protein in the liver of patients with chronic hepatitis $\mathrm{C}$ correlates with a reduced activation of the endogenous interferon system. Hepatology 51: 1127-1136.

126. Mazzon M, Jones M, Davidson A, Chain B, Jacobs M (2009) Dengue virus NS5 inhibits interferon-alpha signaling by blocking signal transducer and activator of transcription 2 phosphorylation. J Infect Dis 200: 1261-1270.

127. Feng $X$, Ratner L (2008) Human T-cell leukemia virus type 1 blunts signaling by interferon alpha. Virology 374: 210-216.

128. Lefort S, A Gravel, L Flamand (2010) Repression of interferon-alpha stimulated genes expression by Kaposi's sarcoma-associated herpesvirus K-bZIP protein. Virology 408: 14-30.

129. Meng X, Schoggins J, Rose L, Cao J, Ploss A, et al. (2012) C7L family of poxvirus host range genes inhibits antiviral activities induced by type interferons and interferon regulatory factor 1 . J Virol 86: 4538-4547.

130. Kubota T, Matsuoka M, Chang TH, Tailor P, Sasaki T, et al. (2008) Virus infection triggers SUMOylation of IRF3 and IRF7, leading to the negative regulation of type I interferon gene expression. J Biol Chem 283: 25660-25670.

131. Scholle F, Mason PW (2005) West Nile virus replication interferes with both poly(l:C)-induced interferon gene transcription and response to interferon treatment. Virology 342: 77-87

132. Liu WJ, Wang XJ, Mokhonov VV, Shi PY, Randall R, et al. (2005) Inhibition of interferon signaling by the New York 99 strain and Kunjin subtype of West Nile virus involves blockage of STAT1 and STAT2 activation by nonstructural proteins. J Virol 79: 1934-1942.

133. Diamond MS, Gale M Jr (2012) Cell-intrinsic innate immune control of West Nile virus infection. Trends Immunol 33: 522-530.

134. Laurent-Rolle M, Boer EF, Lubick KJ, Wolfinbarger JB, Carmody AB, et al. (2010) The NS5 protein of the virulent West Nile virus NY99 strain is a potent antagonist of type I interferon-mediated JAK-STAT signaling. J Virol 84: 35033515 .

135. Jones M, Davidson A, Hibbert L, Gruenwald P, Schlaak J, et al. (2005) Dengue virus inhibits alpha interferon signaling by reducing STAT2 expression. J Virol 79: $5414-5420$.
136. Guo JT, Hayashi J, Seeger C (2005) West Nile virus inhibits the signal transduction pathway of alpha interferon. J Virol 79: 1343-1350.

137. Guo CJ, Yang LS, Zhang YF, Wu YY, Weng SP, et al. (2012) A novel vira SOCS from infectious spleen and kidney necrosis virus: interacts with JaK and inhibits IFN-Ît induced Stat1/3 activation. PLoS One 7: e41092.

138. Basler CF (2012) Nipah and hendra virus interactions with the innate immune system. Curr Top Microbiol Immunol 359: 123-152.

139. Oksayan S, Ito N, Moseley G, Blondel D (2012) Subcellular trafficking in rhabdovirus infection and immune evasion: a novel target for therapeutics. Infect Disord Drug Targets 12: 38-58.

140. Morrison J, Aguirre S, Fernandez-Sesma A (2012) Innate immunity evasion by Dengue virus. Viruses 4: 397-413.

141. Hughes R, Towers G, Noursadeghi M (2012) Innate immune interferon responses to human immunodeficiency virus-1 infection. Rev Med Virol 22 257-266.

142. Thimme R, Binder M, Bartenschlager R (2012) Failure of innate and adaptive immune responses in controlling hepatitis $C$ virus infection. FEMS Microbiol Rev 36: 663-683.

143. García-Sastre A (2011) Induction and evasion of type I interferon responses by influenza viruses. Virus Res 162: 12-18.

144. Schoggins JW, Wilson SJ, Panis M, Murphy MY, Jones CT, et al. (2011) A diverse range of gene products are effectors of the type I interferon antiviral response. Nature 472: 481-485.

145. Liu SY, Sanchez DJ, Aliyari R, Lu S, Cheng G (2012) Systematic identification of type I and type II interferon-induced antiviral factors. Proc Natl Acad Sci U A 109: 4239-4244.

146. Welsch C, Jesudian A, Zeuzem S, Jacobson I (2012) New direct-acting antivira agents for the treatment of hepatitis $C$ virus infection and perspectives. Gut 61 Suppl 1: i36-46.

147. Fusco DN, Chung RT (2011) New protease inhibitors for HCV--help is on the way. J Hepatol 54: 1087-1089.

148. Afdhal N, Reddy KR, Nelson DR, Lawitz E, Gordon SC, et al. (2014) Ledipasvir and sofosbuvir for previously treated HCV genotype 1 infection. N Engl J Med 370: 1483-1493.

149. Afdhal N, Zeuzem S, Kwo P, Chojkier M, Gitlin N, et al. (2014) Ledipasvir and sofosbuvir for untreated HCV genotype 1 infection. N Engl J Med 370: 1889-1898.

150. Muñoz-Jordán JL (2010) Subversion of interferon by dengue virus. Curr Top Microbiol Immunol 338: 35-44.

151.Muñoz-Jordán JL, Laurent-Rolle M, Ashour J, Martínez-Sobrido L, Ashok M, et al. (2005) Inhibition of alpha/beta interferon signaling by the NS4B protein of flaviviruses. J Virol 79: 8004-8013.

152. Arnaud N, Dabo S, Maillard P, Budkowska A, Kalliampakou KI, et al. (2010) Hepatitis $C$ virus controls interferon production through PKR activation. PLoS One 5: e10575.

153. Meylan E, Curran J, Hofmann K, Moradpour D, Binder M, et al. (2005) Cardif is an adaptor protein in the RIG-I antiviral pathway and is targeted by hepatitis C virus. Nature 437: 1167-1172.

154. Garaigorta U, Chisari FV (2009) Hepatitis C virus blocks interferon effecto function by inducing protein kinase R phosphorylation. Cell Host Microbe 6 : 513-522.

155. Diamond MS, Roberts TG, Edgil D, Lu B, Ernst J, et al. (2000) Modulation of Dengue virus infection in human cells by alpha, beta, and gamma interferons. J Virol 74: 4957-4966.

156. Ajariyakhajorn C, Mammen MP, Endy TP, Gettayacamin M, Nisalak A et al. ( 2005) Randomized, placebo-controlled trial of nonpegylated and pegylated forms of recombinant human alpha interferon 2a for suppression of dengue virus viremia in rhesus monkeys. Antimicrob Agents Chemother. 49: 45084514

157. Smith JL, Stein DA, Shum D, Fischer MA, Radu C, et al. (2014) Inhibition of dengue virus replication by a class of small-molecule compounds that antagonize dopamine receptor $\mathrm{d} 4$ and downstream mitogen-activated protein kinase signaling. J Virol 88: 5533-5542. 
Citation: Fusco DN, Chung RT (2014) Review of Current Dengue Treatment and Therapeutics in Development. J Bioanal Biomed S8: 002. doi:10.4172/1948-593X.S8-002

158. Shum D, Smith JL, Hirsch AJ, Bhinder B, Radu C, et al. (2010) High-content assay to identify inhibitors of dengue virus infection. Assay Drug Dev Technol 8: $553-570$

159. Wagstaff KM, Sivakumaran H, Heaton SM, Harrich D, Jans DA (2012) Ivermectin is a specific inhibitor of importin $\hat{I} \pm / \hat{I}^{2}$-mediated nuclear import able to inhibit replication of HIV-1 and dengue virus. Biochem J 443: 851-856.

160. Tay MY, Fraser JE, Chan WK, Moreland NJ, Rathore AP, et al. (2013) Nuclear localization of dengue virus (DENV) 1-4 non-structural protein 5 ; protection against all 4 DENV serotypes by the inhibitor Ivermectin. Antiviral Res 99 : 301-306.

161. Mastrangelo E, Pezzullo M, De Burghgraeve T, Kaptein S, Pastorino B, et al. (2012) Ivermectin is a potent inhibitor of flavivirus replication specifically targeting NS3 helicase activity: new prospects for an old drug. J Antimicrob Chemother 67: 1884-1894.

162. Salgado D, Zabaleta TE, Hatch S, Vega MR, Rodriguez J (2012) Use of pentoxifylline in treatment of children with dengue hemorrhagic fever. Pediatr Infect Dis J 31: 771-773.

163. Farias KJ, Machado PR, da Fonseca BA (2013) Chloroquine inhibits dengue virus type 2 replication in Vero cells but not in $66 / 36$ cells. ScientificWorldJournal 2013: 282734

164.Savarino A, Boelaert JR, Cassone A, Majori G, Cauda R (2003) Effects of chloroquine on viral infections: an old drug against today's diseases? Lancet Infect Dis 3: 722-727.

165. Navarro-Sanchez E, Altmeyer R, Amara A, Schwartz O, Fieschi F, et al (2003) Dendritic-cell-specific ICAM3-grabbing non-integrin is essential for the productive infection of human dendritic cells by mosquito-cell-derived dengue viruses. EMBO Rep 4: 723-728.

166. Tricou V, Minh NN, Van TP, Lee SJ, Farrar J, et al. (2010) A randomized controlled trial of chloroquine for the treatment of dengue in Vietnamese adults. PLoS Negl Trop Dis 4: e785.

167. Idrees S, Ashfaq UA, Khaliq S (2013) RNAi: antiviral therapy against dengue virus. Asian Pac J Trop Biomed 3: 232-236.

168. Zhang W, Singam R, Hellermann G, Kong X, Juan HS, et al. (2004) Attenuation of dengue virus infection by adeno-associated virus-mediated siRNA delivery. Genet Vaccines Ther 2: 8 .

169. Stein DA, Perry ST, Buck MD, Oehmen CS, Fischer MA, et al. (2011) Inhibition of dengue virus infections in cell cultures and in AG129 mice by a small interfering RNA targeting a highly conserved sequence. J Virol 85: 10154 10166.

170. Korrapati AB, Swaminathan G, Singh A, Khanna N, Swaminathan S (2012) Adenovirus delivered short hairpin RNA targeting a conserved site in the 5 non-translated region inhibits all four serotypes of dengue viruses. PLoS Negl Trop Dis 6: e1735.

171. Subramanya S, Kim SS, Abraham S, Yao J, Kumar M, et al. (2010) Targeted delivery of small interfering RNA to human dendritic cells to suppress dengue virus infection and associated proinflammatory cytokine production. J Virol 84 2490-2501.

172. Alhoot MA, Wang SM, Sekaran SD (2012) RNA interference mediated inhibition of dengue virus multiplication and entry in HepG2 cells. PLoS One 7: e34060.

173. Padwad YS, Mishra KP Jain M, Chanda S, Karan D et al (2009) RNA interference mediated silencing of $\mathrm{Hsp60}$ gene in human monocytic myeloma cell line U937 revealed decreased dengue virus multiplication. Immunobiology 214: $422-429$.
174. Kakumani PK, Ponia SS, S RK, Sood V, Chinnappan M, et al. (2013) Role of RNA interference (RNAi) in dengue virus replication and identification of NS4B as an RNAi suppressor. J Virol 87: 8870-8883.

175. Kinney RM, Huang CY, Rose BC, Kroeker AD, Dreher TW, et al. (2005) Inhibition of dengue virus serotypes 1 to 4 in vero cell cultures with morpholino oligomers. J Virol 79: 5116-5128.

176. Stein DA, Huang CY, Silengo S, Amantana A, Crumley S, et al. (2008) Treatment of AG129 mice with antisense morpholino oligomers increases survival time following challenge with dengue 2 virus. J Antimicrob Chemother 62: 555-565.

177. Holden KL, Stein DA, Pierson TC, Ahmed AA, Clyde K, et al. (2006) Inhibition of dengue virus translation and RNA synthesis by a morpholino oligomer targeted to the top of the terminal 3' stem-loop structure. Virology 344: 439452.

178. Raviprakash K, Liu K, Matteucci M, Wagner R, Riffenburgh R, et al. (1995) nhibition of dengue virus by novel, modified antisense oligonucleotides. J Virol 69: 69-74.

179.Zhang XG, Mason PW, Dubovi EJ, Xu X, Bourne N, et al. (2009) Antiviral activity of geneticin against dengue virus. Antiviral Res 83: 21-27.

180. Aman MJ, Kinch MS, Warfield K, Warren T, Yunus A, et al. (2009) Development of a broad-spectrum antiviral with activity against Ebola virus. Antiviral Res 83: 245-251.

181. Abd Kadir SL, Yaakob H, Mohamed Zulkifli R (2013) Potential anti-dengue medicinal plants: a review. J Nat Med 67: 677-689.

182. Tang LI, Ling AP, Koh RY, Chye SM, Voon KG (2012) Screening of antidengue activity in methanolic extracts of medicinal plants. BMC Complement Altern Med 12: 3

183. Koishi AC, Zanello PR, Bianco ÉM, Bordignon J, Nunes Duarte dos Santos C (2012) Screening of Dengue virus antiviral activity of marine seaweeds by an in situ enzyme-linked immunosorbent assay. PLoS One 7: e51089.

184. Padilla-S L, Rodríguez A, Gonzales MM, Gallego-G JC, Castano-O JC (2014) Inhibitory effects of curcumin on dengue virus type 2-infected cells in vitro. Arch Virol 159: 573-579.

185. Lee SH, Tang YQ, Rathkrishnan A, Wang SM, Ong KC, et al. (2013) Effects of cocktail of four local Malaysian medicinal plants (Phyllanthus spp.) against dengue virus 2. BMC Complement Altern Med 13: 192.

186. Lin LT, Chen TY, Lin SC, Chung CY, Lin TC, et al. (2013) Broad-spectrum antiviral activity of chebulagic acid and punicalagin against viruses that use glycosaminoglycans for entry. BMC Microbiol 13: 187.

187. Ahmad N, Fazal H, Ayaz M, Abbasi BH, Mohammad I, et al. (2011) Dengue fever treatment with Carica papaya leaves extracts. Asian Pac J Trop Biomed 1: $330-333$

This article was originally published in a special issue, Advances in Drug Development: Novel Antiviral Agents handled by Editor(s). Dr. Erik de Leeuw, University of Maryland Baltimore School of Medicine, USA 